\title{
Association between lifestyle, menstrual/reproductive history, and histological factors and risk of breast cancer in women biopsied for benign breast disease
}

\author{
Rhonda Arthur ${ }^{1}$, Yihong Wang ${ }^{2}$, Kenny Ye $^{1}$, Andrew G. Glass ${ }^{3}$, Mindy Ginsberg ${ }^{1}$, Olivier \\ Loudig $^{1}$, and Thomas Rohan ${ }^{1}$ \\ ${ }^{1}$ Department of Epidemiology and Population Health, Albert Einstein College of Medicine, Bronx, \\ New York, 10461 \\ ${ }^{2}$ Department of Pathology and Laboratory Medicine, Rhode Island Hospital and Lifespan Medical \\ Center, Warren Alpert Medical School of Brown University, Providence, RI 02903 \\ ${ }^{3}$ Center for Health Research, Kaiser Permanente Northwest, Portland, Oregon
}

\begin{abstract}
Purpose-Women with benign breast disease (BBD) have an increased risk of subsequent breast cancer. However, whether conventional breast cancer risk factors influence risk of breast cancer among women with BBD is unclear. In this study, we investigated the associations of lifestyle, menstrual/reproductive, and histological factors with risk of breast cancer among women biopsied for BBD.

Methods-We conducted a case-control study, nested within a cohort of 15,395 women biopsied for BBD at Kaiser Permanente Northwest between 1971 and 2006. Cases were women who developed a subsequent invasive breast cancer during follow-up; controls were individually matched to cases on age at BBD diagnosis. A total of 526 case-control pairs were included in the study. We calculated crude and multivariable OR and 95\% CI for the associations between lifestyle, menstrual/reproductive, and histological factors and breast cancer risk using conditional logistic regression.
\end{abstract}

Results-Compared to premenopausal women, postmenopausal women, had reduced risk of subsequent breast cancer (OR: 0.60; 95\% CI: 0.39-0.94), whereas women who ever used hormone therapy had increased risk (OR: $3.61 ; 95 \%$ CI: 1.68-7.75), as did women whose BBD lesion showed atypical hyperplasia (OR: 5.56; 95\% CI: 2.05-15.06). Smoking, BMI, early menarche, multiparity $(>=4)$, history of oophorectomy, and extent of lobular involution were not associated with risk of breast cancer.

Conclusion-This study suggests that use of HRT and having atypical hyperplasia are associated with increased risk of breast cancer among women with BBD while postmenopausal women with BBD have a reduced risk.

Corresponding author: Rhonda Arthur Department of Epidemiology and Population Health Albert Einstein College of Medicine, 1300 Morris Park, Ave. Bronx, NY 10461, Tel.: 1-718-430-3038, Fax: 1-718-430-8653, rhonda.arthur@einstein.yu.edu.

Conflict of interests: None declared. 


\section{Keywords}

breast cancer; benign breast disease; lifestyle factors; reproductive factors; histological factors

\section{Introduction}

Women with benign breast disease (BBD) have a two-fold increase in risk of subsequent invasive breast cancer $(1,2)$. Risk varies by histological characteristics of the BBD, and is particularly high in women with atypical hyperplasia, who have been shown to have a fourto five-fold increase in breast cancer risk (3). However, women with BBD do not necessarily progress to invasive breast cancer. Hence, other factors must also influence the likelihood of progression. In this regard, to date, only a few studies have examined the role that established breast cancer risk factors play in modulating the risk of breast cancer among women with BBD, and the evidence remains inconclusive (4-9). In addition, other histologic features such as lobular involution, which is characterized by progressive loss of breast epithelial cells with increasing age, may also affect risk of breast cancer $(10,11)$, but little is known about the association between lobular involution and breast cancer risk in this group of women.

Given the paucity of existing data on risk factors for breast cancer in women diagnosed with BBD, we investigated the association between histological characteristics, lifestyle factors, and menstrual and reproductive history, and breast cancer risk in a large cohort of women with BBD.

\section{Materials and Methods}

\section{Study population and design}

We conducted our investigation by performing a case-control study nested within a cohort of women who had a biopsy for benign breast disease (BBD) within the Kaiser Permanente Northwest Region (KPNW) health care system. KPNW is a prepaid health plan that provides comprehensive medical care for over 500,000 members in facilities located in Southwest Washington and Northwest Oregon.

\section{Cohort definition}

The cohort consisted of the 15,395 women aged 21 to 85 years who received a histopathologic diagnosis of BBD at KPNW between August 3, 1971 and December 31, 2006 and were followed until July 1, 2015. Women were excluded from the study if they: (i) were diagnosed with invasive breast cancer prior to or within one year of their first biopsy for BBD (N=3); (ii) had carcinoma in situ prior to their first biopsy for BBD (N=4); (iii) had no breast tissue in their biopsy ( $\mathrm{N}=79)$; (iv) had no risk factor information $(\mathrm{N}=15)$; or $(\mathrm{v})$ if their matched pair was missing $(\mathrm{N}=38)$.

\section{Case definition, ascertainment, and selection}

Cases were women with a biopsy for BBD and with a subsequent first diagnosis of invasive breast cancer at least one year after the index BBD biopsy. The occurrence of breast cancer 
in the cohort was ascertained by linking records from the BBD cohort to the KPNW Tumor Registry. The KPNW Tumor Registry has operated continuously since 1960 and is approved by the Commission on Cancer of the American College of Surgeons. It was computerized in 1978 and includes all cases diagnosed since 1960. Cases of cancer are identified primarily from pathology reports forwarded directly from the Department of Pathology at KPNW to the Tumor Registry at the time of diagnosis. These cases are supplemented by examination of the inpatient discharge logs, referrals to radiation oncologists, and surveillance of radiology reports marked as particularly suspicious for cancer. The terms of insurance coverage by Kaiser Permanente serve to concentrate members' medical care within the walls of KPNW, particularly for chronic diseases such as cancer. The KPNW Tumor Registry has an excellent follow-up rate, even for women who are no longer health plan members, and it has maintained a follow-up rate of $98 \%$ of patients (living and dead) enrolled since its reference date of 1960 .

\section{Control definition and selection}

Controls were women with a biopsy for BBD who were alive but had not developed breast cancer during the same follow-up period as that for the corresponding cases. For each of the cases, we randomly selected one control using risk-set sampling. Each control was individually matched to the corresponding case on age at diagnosis of BBD (+/- 1 year) (and implicitly, given the risk-set sampling, on duration of membership of KPNW), and was sampled randomly from the risk-set with replacement (12). In addition to being alive and free of invasive breast cancer, each control was required not to have undergone a mastectomy before the date of diagnosis of breast cancer for its matched case.

\section{Risk factor data}

KPNW uses unique and permanent health record numbers to identify all members. All encounters with the medical care system - clinic visit, prescription, operation, laboratory test, and so on - are linked by this identification number and are recorded in the single health record. For the present study, risk factor information was obtained by abstracting data from the KPNW medical records using a chart abstraction manual. This yielded information on age at menarche; age at first live birth; number of pregnancies; menopausal status; family history of breast cancer in a first degree relative; height; weight; ever use and duration of use of cigarettes and number of cigarettes smoked per day; ever use and duration of use of hormone replacement therapy (HRT); and history of and date of bilateral oophorectomy and hysterectomy.

\section{Tissue acquisition}

The KPNW Department of Pathology has retained slides of all its cases since 1970. The files of slides are complete and are easily accessed. Blocks are similarly available and archived in the KPNW warehouse adjacent to the pathology laboratory. For subjects selected for inclusion in the study described here, attempts were made to retrieve tissue blocks from the archives. 


\section{Histopathology}

Hematoxylin and eosin sections, prepared from the BBD tissue blocks, were reviewed by a breast pathologist who was blinded to the case-control status of the study subjects. The BBD lesions were classified according to the well-established criteria of Page and colleagues (1316) as follows: no lesions/non-proliferative lesions (cysts, fibrosis, apocrine metaplasia, adenosis, simple fibroadenoma); proliferative disease without atypia (mild, moderate, or florid epithelial hyperplasia; columnar cell change and columnar cell hyperplasia; complex fibroadenoma; sclerosing adenosis; radial scar; complex sclerosing lesion, papilloma); and proliferative disease with atypia (atypical ductal hyperplasia, atypical lobular hyperplasia, columnar cell change and columnar cell hyperplasia with atypia/and flat epithelial atypia). Each biopsy specimen was further categorized for lobular involution (absent, 1-74\%, $275 \%$, not assessable) (10).

\section{Statistical analysis}

Conditional logistic regression was performed to estimate the crude and multivariable odds ratios (OR) and 95\% confidence intervals (CI) for the associations of lifestyle factors, family history of breast cancer, menstrual/reproductive factors and histological factors with breast cancer risk. Specifically, the following variables were examined: cigarette smoking status (yes/no), pack-years of cigarette smoking (never, >0-10, >10-20, >20-30, >30-40, >40), BMI $\left(<18.5,18.5-24.9,25-29.9, \geq 30 \mathrm{~kg} / \mathrm{m}^{2}\right)$, family history of breast cancer in a first degree female relative (yes/no), age at menarche $(<11,12-13, \geq 14$ years), age at first live birth (never had, 15-19, 20-24, 25-29, 230 years), number of pregnancies (never pregnant, $1,2,3, \geq 4$ ), oophorectomy (yes/no), HRT use (yes/no), duration of HRT use (never, $>0-9$, 10-20, >20 years, BBD (no lesions/non-proliferative lesions; proliferative disease without atypia; and atypical hyperplasia), and lobular involution (yes/no; absent, 1-74\% and $275 \%$ ).

Results for each variable are presented as both crude (univariate) ORs, and as multivariable ORs that are adjusted for the other variables of interest. Age at first live birth and number of pregnancies are strongly correlated with each other. Hence, to deal with the issue of collinearity between these variables, we included them as a compound variable in the multivariable model (nulliparous; age at first live birth $\geq 25$ years and number of pregnancies $<3$; age at first live birth $\geq 25$ years and number of pregnancies 23 ; age at first live birth $<25$ years and number of pregnancies $<3$; age at first live birth $<25$ years and number of pregnancies 23$)(5)$. When age at first live birth or number of pregnancies was assessed as the main exposure, the aforementioned compound variable was excluded from the multivariable model. All variables with missing information were assigned a missing value indicator for the analyses.

Finally, we conducted stratified analyses to assess whether the associations between the risk factor variables and breast cancer differed by BBD type (non-proliferative versus proliferative disease (with and without atypia) and menopausal status (premenopausal and postmenopausal) using unconditional logistic regression. The unconditional logistic regression models were adjusted for the same covariates as the multivariate conditional logistic regression models (unless included as the main exposure) in addition to the matching factor (age at diagnosis of BBD). 
To assess trend in risk across consecutive levels of the categorical variables, each category was allocated an ordinal number. The exposures were then fitted as continuous variables in the models and Wald tests were used to assess statistical significance. The missing value indicator was excluded from all tests for trend.

The statistical analyses were conducted using Stata 14.1 (StataCorp, College Station, TX, USA). P values $<0.05$ were considered to be statistically significant.

\section{Results}

\section{Benign breast disease histology}

Epithelial hyperplasia without atypia was not associated with altered risk of breast cancer (Table 1). Women with atypical hyperplasia, however, had a five-fold increased risk of subsequent invasive breast cancer (adjusted OR: 5.56; 95\% CI: 2.05-15.06).

\section{Lifestyle factors and family history}

There were no differences in the risk of breast cancer between cases and controls by smoking status, pack years of cigarette smoking, BMI or family history of breast cancer in a first degree relative (Table 2).

These associations also did not vary by BBD type (Supplementary Table 1) or by menopausal status (results not shown).

\section{Reproductive factors}

After adjustment for smoking history, BMI, age at menarche, menopausal status, history of oophorectomy, family history, hormonal therapy use and benign disease histology, all categories of age at first live birth and number of pregnancies were at reduced risk of breast cancer compared to that for nulliparous women (Table 3). Being perimenopausal or postmenopausal was also inversely associated with breast cancer in both univariate and multivariable analyses (perimenopausal- adjusted OR: 0.28 ; 95\% CI: 0.09-0.92, postmenopausal- adjusted OR: 0.60; 95\% CI: 0.39-0.94). However, there was little alteration in risk in association with early age at menarche $(<11)$, early age $(15-19$ years $)$ and late ( $>30$ years) age at first birth, and a relatively large number of pregnancies ( $\geq$ ). Women who had ever used hormone therapy had a substantial increase in risk of breast cancer compared to never users (adjusted OR: $3.61 ; 95 \%$ CI: $1.68-7.75$ ) although there was no trend in risk with duration of use. There was some suggestion of a reduction in risk in association with a history of bilateral oophorectomy (albeit not statistically significant).

In analyses stratified by BBD type, the inverse association for postmenopausal women was evident only in those with proliferative disease (with and without atypia) (adjusted OR: 0.53; 95\% CI: 0.34-0.83), as was the positive association with hormone therapy use (adjusted OR: 3.99; 95\% CI: 1.80-8.82) (Supplementary Table 2). The associations between the remaining reproductive factors and risk of breast cancer did not vary by BBD type. When the analyses were stratified by menopausal status, there were no associations between menstrual/ reproductive factors (age at menarche, age at first live birth, number of pregnancies, history 
of oophorectomy, hormonal therapy use and duration of hormonal therapy use) and risk of breast cancer (results not shown).

\section{Lobular involution}

A statistically non-significant inverse association was seen between lobular involution and breast cancer risk (Table 4). When considering the extent of lobular involution, a similar statistically non-significant inverse association was apparent, although the association was attenuated in the multivariate model.

\section{Discussion}

This large, nested case-control study is one of only a few studies that has examined the association between classical breast cancer risk factors and breast cancer risk among women with $\operatorname{BBD}(4,5,17,18)$. Our results suggest that being postmenopausal is associated with reduced risk of subsequent invasive breast cancer in women with BBD, while ever use of hormone therapy, and BBD lesions showing atypical hyperplasia are associated with an increased risk of subsequent breast cancer development. When stratified by BBD histology, the reduction in risk for postmenopausal women was restricted to those with proliferative disease, as was the increase in risk in association with ever use of HRT. The associations between the lifestyle or menstrual/reproductive factors and risk of breast cancer, however, did not vary by menopausal status (results not shown). Early age at menarche, early age at first live birth, having a higher number of pregnancies, history of oophorectomy, and lobular involution were not associated with risk of breast cancer.

\section{Smoking status, BMI and family history}

Similar to the results of Kabat and colleagues (5), our study did not find any association between smoking history or pack-years of cigarette smoking and breast cancer risk among women with BBD. Research on smoking as a risk factor for invasive breast cancer remains inconclusive, but several recent studies have reported a positive association between smoking and breast cancer risk (19-21). Family history of breast cancer and obesity are better established risk factors for breast cancer (22-24). In keeping with findings from previous studies $(5,17,25)$, there was no evidence from this study to support an association between obesity or family history and breast cancer risk among women with BBD overall. However, contrary to our finding of a null association between family history and breast cancer risk among women with proliferative BBD, several studies have provided evidence in support of elevated risk of breast cancer in relation to a positive family history of breast cancer $(17,26,27)$. However, further studies are needed to confirm this.

\section{Reproductive factors}

Women who have an early age at first live birth, have a history of bilateral oophorectomy, or have a relatively large number of pregnancies have been shown to have reduced risk of breast cancer, while risk is increased in those who experience early menarche $(22,23,28)$. However, the role of these reproductive factors in affecting breast cancer risk among women with BBD is underexplored. One early study reported that women with atypical hyperplasia who were nulliparous had a five-fold increased risk of breast cancer (4). Previously, Kabat et 
al. also demonstrated that reproductive factors, including relatively early age at first live birth and having a relatively large number of pregnancies, may confer reductions in breast cancer risk among women with a history of BBD (5). We saw similar inverse associations in the current study for early age at first live birth and having a relatively large number of pregnancies, but the associations were not statistically significant.

In line with our findings, Kabat et al. also reported that postmenopausal women with BBD had lower risk of breast cancer compared to premenopausal women (5). In further analyses, we showed that the association with postmenopausal status appeared to be confined to those with proliferative BBD. These findings suggest that the association between having a previous BBD and subsequent development of breast cancer may be mediated by menopausal status. The observed inverse association with menopausal status may be partly driven by the reduction in circulating estrogen levels that occurs in association with menopause $(29,30)$.

Evidence on the association between HRT use and breast cancer risk among women with BBD remains inconsistent. Contrary to our study, in which we observed a strong positive association, two studies provided null findings for the association between HRT use and breast cancer among women with $\operatorname{BBD}(5,31)$, while inverse associations were reported by two earlier studies $(32,33)$. Nonetheless, findings from our study are consistent with those from previous studies which indicate a greater risk of breast cancer among HRT users than non-users (34-36). Unlike the Collaborative Group on Hormonal Factors in Breast Cancer study and more recent studies $(34,37,38)$, which have reported that longer duration of HRT use is associated with increased risk of breast, we did not observe any association between duration of use and breast cancer. Nonetheless, the positive association observed in this study between HRT use and breast cancer risk is in accord with biologically plausible evidence which suggests that hormones such as estrogen may induce breast carcinogenesis by promoting tumor cell proliferation and migration (39-41). The increased risk may also be partly due to the fact that HRT has been postulated to increase breast density, thus reducing the sensitivity and specificity of the breast screening (22).

\section{Breast histology}

Similar to previous studies, the current study showed an increased risk of breast cancer among women with epithelial hyperplasia without atypia although the association was not statistically significant $(1-3,13,42,43)$. However, there was a very strong, statistically significant positive association between atypical hyperplasia and risk. The latter finding is in agreement with those of previous studies $(1,2,13,42,43)$. Although only a small proportion of women with BBD are diagnosed with atypical hyperplasia, this lesion is potentially clinically relevant as it has been hypothesized that it may be a premalignant lesion, given that it contains some of the features that characterize breast cancers $(44,45)$.

In contrast to proliferative benign breast disease, lobular involution has been associated with reduced risk of breast cancer $(10,46)$. Although the association between lobular involution and breast cancer was not statistically significant in our study, there was some suggestion of an inverse association, as observed in previous studies involving women with BBD $(10,11)$. 


\section{Strengths and Limitations}

This study has several strengths. The study was conducted in a defined population, the sample size was substantial, and the benign breast lesions were subjected to standardized histological review conducted by a pathologist blinded to case-control status. Also, the risk factor information was collected using a standardized chart abstraction form to obtain data from the KPNW medical records, which have been shown to be of high quality $(47,48)$.

Concerning limitations, although the study was relatively large, we had limited power to perform stratified analyses separately for those with and without atypical hyperplasia. Also, for some of the variables examined, the proportion of missing values was relatively large.

\section{Conclusion}

Our findings suggest that risk of subsequent invasive breast cancer in women with BBD is associated with several other factors. Specifically, amongst women with BBD, risk of breast cancer is decreased in those who are postmenopausal, and increased in those who have ever used HRT. Both of these associations appeared to be particularly evident amongst those with proliferative forms of BBD. Antecedent BBD, and particularly atypical hyperplasia, rendered women at substantially increased risk for breast cancer. Further work is needed to elucidate how BBD combines with other breast cancer risk factors to influence breast cancer risk. Such knowledge may be useful in guiding interventions aimed at preventing progression to invasive breast cancer. However, full elucidation of the complex interplay between these factors will require larger studies.

\section{Supplementary Material}

Refer to Web version on PubMed Central for supplementary material.

\section{Acknowledgments}

Funding Information

This work was supported by NIH/NCI grant R01CA142942 (to T.E. Rohan). Drs. Arthur and Rohan are supported by the Breast Cancer Research Foundation. We would particularly like to thank the following staff at the Kaiser Center for Health Research who worked on this project for several years: Nicole Bennett, Kristine Bennett, Donna Gleason, Kathy Pearson, Tracy Dodge, Stacy Harsh and Kevin Winn.

\section{References}

1. Goldacre MJ, Abisgold JD, Yeates DGR, Vessey MP. Benign breast disease and subsequent breast cancer: English record linkage studies. J Public Health Med. 2010; 32:565-571. DOI: 10.1093/ pubmed/fdq001

2. Tice JA, O'Meara ES, Weaver DL, Vachon C, Ballard-Barbash R, Kerlikowske K. Benign Breast Disease, Mammographic Breast Density, and the Risk of Breast Cancer. JNCI. 2013; 105:10431049. DOI: 10.1093/jnci/djt124 [PubMed: 23744877]

3. Cuzick J, Sestak I, Thorat MA. Impact of preventive therapy on the risk of breast cancer among women with benign breast disease. Breast 24 Supplt. 2015; 2:S51-S55. DOI: 10.1016/j.breast. 2015.07.013

4. Dupont WD, Page DL. Breast cancer risk associated with proliferative disease, age at first birth, and a family history of breast cancer. Am J Epidemiol. 1987; 125:769-779. [PubMed: 3565352] 
5. Kabat GC, Jones JG, Olson N, Negassa A, Duggan C, Ginsberg M, et al. Risk factors for breast cancer in women biopsied for benign breast disease: A nested case-control study. Cancer Epidemiol. 2010; 34:34-39. DOI: 10.1016/j.canep.2009.12.005 [PubMed: 20079704]

6. Thomas DB, Persing JP, Hutchinson WB. Exogenous Estrogens and Other Risk Factors for Breast Cancer in Women With Benign Breast Diseases. JNCI. 1982; 69:1017-1025. https://doi.org/ 10.1093/jnci/69.5.1017. [PubMed: 6957648]

7. Byrne C, Connolly JL, Colditz GA, Schnitt SJ. Biopsy confirmed benign breast disease, postmenopausal use of exogenous female hormones, and breast carcinoma risk. Cancer. 2000; 89:2046-2052. DOI: 10.1002/1097-0142(20001115)89:10<2046::aid-cncr3>3.0.co;2-f [PubMed: 11066044]

8. Horn-Ross P, Canchola AJ, West DW, Stewart SL, Bernstein L, Deapen D, et al. Patterns of Alcohol Consumption and Breast Cancer Risk in the California Teachers Study Cohort. Cancer Epidemiol Biomarkers Prev. 2004; 13:405. [PubMed: 15006916]

9. van dB, Goldbohm RA, van 't Veer P. Alcohol and Breast Cancer: Results from the Netherlands Cohort Study. Am J Epidemiol. 1995; 141:907-915. doi: https://doi.org/10.1093/ oxfordjournals.aje.a117357. [PubMed: 7741120]

10. Milanese TR, Hartmann LC, Sellers TA, Frost MH, Vierkant RA, Maloney SD, et al. Age-related lobular involution and risk of breast cancer. JNCI. 2006; 98:1600-1607. doi: https://doi.org/ 10.1093/jnci/djj439. [PubMed: 17105983]

11. Radisky DC, Visscher DW, Frank RD, Vierkant RA, Winham S, Stallings-Mann M, et al. Natural history of age-related lobular involution and impact on breast cancer risk. Breast Cancer Res Treat. 2016; 155:423-430. DOI: 10.1007/s10549-016-3691-5 [PubMed: 26846985]

12. Rothman, K., Greenland, S., Lash, T. Modern epidemiology. Lippincott Williams \& Wilkins; Philadelphia: 2008.

13. Hartmann LC, Sellers TA, Frost MH, Lingle WL, Degnim AC, Ghosh K, et al. Benign breast disease and the risk of breast cancer. N Engl J Med. 2005; 353:229-237. DOI: 10.1056/ NEJMoa044383 [PubMed: 16034008]

14. Page, OL., Anderson, TJ. Diagnostic histopathology of the breast. Churchill Livingstone; Edinburgh: 1987.

15. Page DL, Rogers LW. Combined histologic and cytologic criteria for the diagnosis of mammary atypical ductal hyperplasia. Hum Pathol. 1992; 23:1095-1097. doi:https://doi.org/ 10.1016/0046-8177(92)90026-Y. [PubMed: 1328030]

16. Page DL, Schuyler PA, Dupont WD, Jensen RA, Plummer WD Jr, Simpson JF. Atypical lobular hyperplasia as a unilateral predictor of breast cancer risk: a retrospective cohort study. Lancet. 2003; 361:125-129. doi: http://dx.doi.org/10.1016/S0140-6736(03)12230-1. [PubMed: 12531579]

17. Collins LC, Baer HJ, Tamimi RM, Connolly JL, Colditz GA, Schnitt SJ. The influence of family history on breast cancer risk in women with biopsy-confirmed benign breast disease. Cancer. 2006; 107:1240-1247. DOI: 10.1002/cncr.22136 [PubMed: 16902983]

18. Zhou W, Xue D, Liu X, Ding Q, Wang S. The influence of family history and histological stratification on breast cancer risk in women with benign breast disease: A meta-analysis. J Cancer Res Clin Oncol. 2011; 137:1053-1060. DOI: 10.1007/s00432-011-0979-z [PubMed: 21499874]

19. Catsburg C, Miller AB, Rohan TE. Active cigarette smoking and risk of breast cancer. Int J Cancer. 2015; 136:2204-2209. DOI: 10.1002/ijc.29266 [PubMed: 25307527]

20. Dossus L, Boutron-Ruault M, Kaaks R, Gram IT, Vilier A, Fervers B, et al. Active and passive cigarette smoking and breast cancer risk: Results from the EPIC cohort. Int J Cancer. 2014; 134:1871-1888. [PubMed: 24590452]

21. Johnson KC, Miller AB, Collishaw NE, Palmer JR, Hammond SK, Salmon AG, et al. Active smoking and secondhand smoke increase breast cancer risk: the report of the Canadian Expert Panel on Tobacco Smoke and Breast Cancer Risk (2009). Tob Control. 2011; 20:e2. http:// dx.doi.org/10.1136/tc.2010.035931.

22. McPherson K, Steel CM, Dixon JM. Breast cancer- Epidemiology, risk factors, and genetics. BMJ. 2000; 321:624-628. doi: https://doi.org/10.1136/bmj.321.7261.624. [PubMed: 10977847]

23. Hulka BS, Moorman PG. Reprint of Breast cancer: hormones and other risk factors. Maturitas. 2008; 61:203-213. doi: http://dx.doi.org/10.1016/j.maturitas.2008.11.016. [PubMed: 19434892] 
24. Kyrgiou M, Kalliala I, Markozannes G, Gunter MJ, Paraskevaidis E, Gabra H, et al. Adiposity and cancer at major anatomical sites: Umbrella review of the literature. 2017; 356:j477. doi: https:// doi.org/10.1136/bmj.j477.

25. Degnim AC, Visscher DW, Berman HK, Frost MH, Sellers TA, Vierkant RA, et al. Stratification of Breast Cancer Risk in Women With Atypia: A Mayo Cohort Study. J Clin Oncol. 2007; 25:26712677. DOI: 10.1200/JCO.2006.09.0217 [PubMed: 17563394]

26. Webb PM, Byrne C, Schnitt SJ, Connolly JL, Jacobs T, Peiro G, et al. Family history of breast cancer, age and benign breast disease. Int J Cancer. 2002; 100:375-378. DOI: 10.1002/ijc.10490 [PubMed: 12115556]

27. Castells X, Domingo L, Corominas JM, Torá-Rocamora I, Quintana MJ, Baré M, et al. Breast cancer risk after diagnosis by screening mammography of nonproliferative or proliferative benign breast disease: a study from a population-based screening program. Breast Cancer Res Treat. 2015; 149:237-244. DOI: 10.1007/s10549-014-3208-z [PubMed: 25503778]

28. Kapil U, Bhadoria AS, Sareen N, Singh P, Dwivedi SN. Reproductive factors and risk of breast cancer: A Review. Indian J Cancer. 2014; 51:571-576. DOI: 10.4103/0019-509X.175345 [PubMed: 26842199]

29. Monninkhof EM, van dS, Peeters PHM. Early age at menopause and breast cancer: are leaner women more protected? A prospective analysis of the Dutch DOM cohort. Breast Cancer Res Treat. 1999; 55:285-291. DOI: 10.1023/A:1006277207963 [PubMed: 10517172]

30. Folkerd E, Dowsett M. Sex hormones and breast cancer risk and prognosis. The Breast Suppl. 2013; 2:S38-S43. DOI: 10.1016/j.breast.2013.07.007

31. Dupont WD, Page DL. Menopausal estrogen replacement therapy and breast cancer. Arch Intern Med. 1991; 151:67-72. DOI: 10.1001/archinte.1991.00400010089011 [PubMed: 1824675]

32. McDonald JA, Weiss NS, Daling JR, Francis AM, Polissar L. Menopausal estrogen use and the risk of breast cancer. Breast Cancer Res Treat. 1986; 7:193-199. DOI: 10.1007/BF01806250 [PubMed: 3779117]

33. Gambrel RJ, Maier R, Sanders B. Decreased incidence of breast cancer in postmenopausal estrogen-progestogen users. Obstet Gynecol. 62:435-443.

34. Collaborative Group on Hormonal Factors in Breast Cancer. Breast cancer and hormone replacement therapy: Collaborative reanalysis of data from 51 epidemiological studies of 52705 women with breast cancer and 108411 women without breast cancer. Lancet. 1997; 350:10471059. doi: http://dx.doi.org/10.1016/S0140-6736(97)08233-0. [PubMed: 10213546]

35. Chlebowski RT, Anderson GL, Gass M, Lane DS, Aragaki AK, Kuller LH, et al. Estrogen plus progestin and breast cancer incidence and mortality in postmenopausal women. JAMA. 2010; 304:1684-1692. DOI: 10.1001/jama.2010.1500 [PubMed: 20959578]

36. Thorbjarnardottir T, Olafsdottir EJ, Valdimarsdottir UA, Olafsson O, Tryggvadottir L. Oral contraceptives, hormone replacement therapy and breast cancer risk: A cohort study of 16928 women 48 years and older. Acta Oncol. 2014; 53:752-758. DOI: 10.3109/0284186X.2013.878471 [PubMed: 24460068]

37. Jones ME, Schoemaker MJ, Wright L, McFadden E, Griffin J, Thomas D, et al. Menopausal hormone therapy and breast cancer: What is the true size of the increased risk. Br J Cancer. 2016; 115:607-615. DOI: 10.1038/bjc.2016.231 [PubMed: 27467055]

38. Coombs NJ, Taylor R, Wilcken N, Fiorica J, Boyages J. Hormone replacement therapy and breast cancer risk in California. Breast J. 2005; 11:410-415. DOI: 10.1111/j.1075-122X.2005.00132.x [PubMed: 16297085]

39. Nandi S, Guzman RC, Yang J. Hormones and mammary carcinogenesis in mice, rats, and humans: A unifying hypothesis. Proc Natl Acad Sci U S A. 1995; 92:3650-3657. DOI: 10.1073/pnas. 92.9.3650 [PubMed: 7731959]

40. Pike MC, Spicer D, Dahmoush L, Press MF. Estrogens, progestogens, normal breast cell proliferation, and breast cancer risk. Epidemiol Rev. 1993; 15:17-35. doi: https://doi.org/10.1093/ oxfordjournals.epirev.a036102. [PubMed: 8405201]

41. Russo J, Fernandez SV, Russo PA, Fernbaugh R, Sheriff FS, Lareef HM, et al. 17-Beta-estradiol induces transformation and tumorigenesis in human breast epithelial cells. FASEB J. 2006; 20:1622-1634. DOI: 10.1096/fj.05-5399com [PubMed: 16873885] 
42. Kabat GC, Jones JG, Olson N, Negassa A, Duggan C, Ginsberg M, et al. A multi-center prospective cohort study of benign breast disease and risk of subsequent breast cancer. Cancer Causes Control. 2010; 21:821-828. DOI: 10.1007/s10552-010-9508-7 [PubMed: 20084540]

43. Dyrstad SW, Yan Y, Fowler AM, Colditz GA. Breast cancer risk associated with benign breast disease: systematic review and meta-analysis. Breast Cancer Res Treat. 2015; 149:569-575. DOI: 10.1007/s10549-014-3254-6 [PubMed: 25636589]

44. Hartmann LC, Degnim AC, Santen RJ, Dupont WD, Ghosh K. Atypical hyperplasia of the breast risk assessment and management options. N Engl J Med. 2015; 372:78-89. DOI: 10.1056/ NEJMsr1407164 [PubMed: 25551530]

45. Ma X, Salunga R, Tuggle JT, Gaudet J, Enright E, McQuary P, et al. Gene expression profiles of human breast cancer progression. Proc Natl Acad Sci. 2003; 100:5974-5979. DOI: 10.1073/pnas. 0931261100 [PubMed: 12714683]

46. Ghosh K, Vachon CM, Pankratz VS, Vierkant RA, Anderson SS, Brandt KR, et al. Independent association of lobular involution and mammographic breast density with breast cancer risk. JNCI. 2010; 102:1716-1723. DOI: 10.1093/jnci/djq414 [PubMed: 21037116]

47. Stevens VJ, Wagner EL, Rossner J, Craddick S, Greenlick MR. Validity and usefulness of medical chart weights in the long-term evaluation of weight loss programs. Addict Behav. 1988; 13:171175. https://doi.org/10.1016/0306-4603(88)90007-X. [PubMed: 3369325]

48. West CN, Geiger AM, Greene SM, Harris EL, Liu IA, Barton MB, et al. Race and ethnicity: Comparing medical records to self-reports. JNCI Monographs. 2005; 2005:72-74. doi: https:// doi.org/10.1093/jncimonographs/lgi041. 


\section{Table 1}

Association between benign breast disease histology and breast cancer risk

\begin{tabular}{|c|c|c|c|c|}
\hline Histologic category & No. of cases & No. of controls & Crude OR (95\% CI) & Multivariable OR (95\% CI) \\
\hline \multicolumn{5}{|l|}{ Benign breast disease } \\
\hline No lesion or non-proliferative lesion ${ }^{*}$ & 87 & 114 & $1.00^{* *}$ & $1.00^{* * *}$ \\
\hline Epithelial hyperplasia without atypia & 411 & 408 & $1.32(0.95-1.82)$ & $1.30(0.90-1.91)$ \\
\hline Atypical hyperplasia & 31 & 7 & $6.13(2.46-15.24)$ & $5.56(2.05-15.06)$ \\
\hline$P$ trend & & & $<0.01$ & $<0.01$ \\
\hline \multicolumn{5}{|l|}{21 cases, 25 controls had no breast lesion } \\
\hline \multicolumn{5}{|c|}{$\begin{array}{l}\text { Adjusted for smoking history, BMI, age at menarche, age at first live birth, number of pregnancies, menopausal status, history of oophorectomy, } \\
\text { family history, hormonal therapy use }\end{array}$} \\
\hline
\end{tabular}


Arthur et al.

Page 13

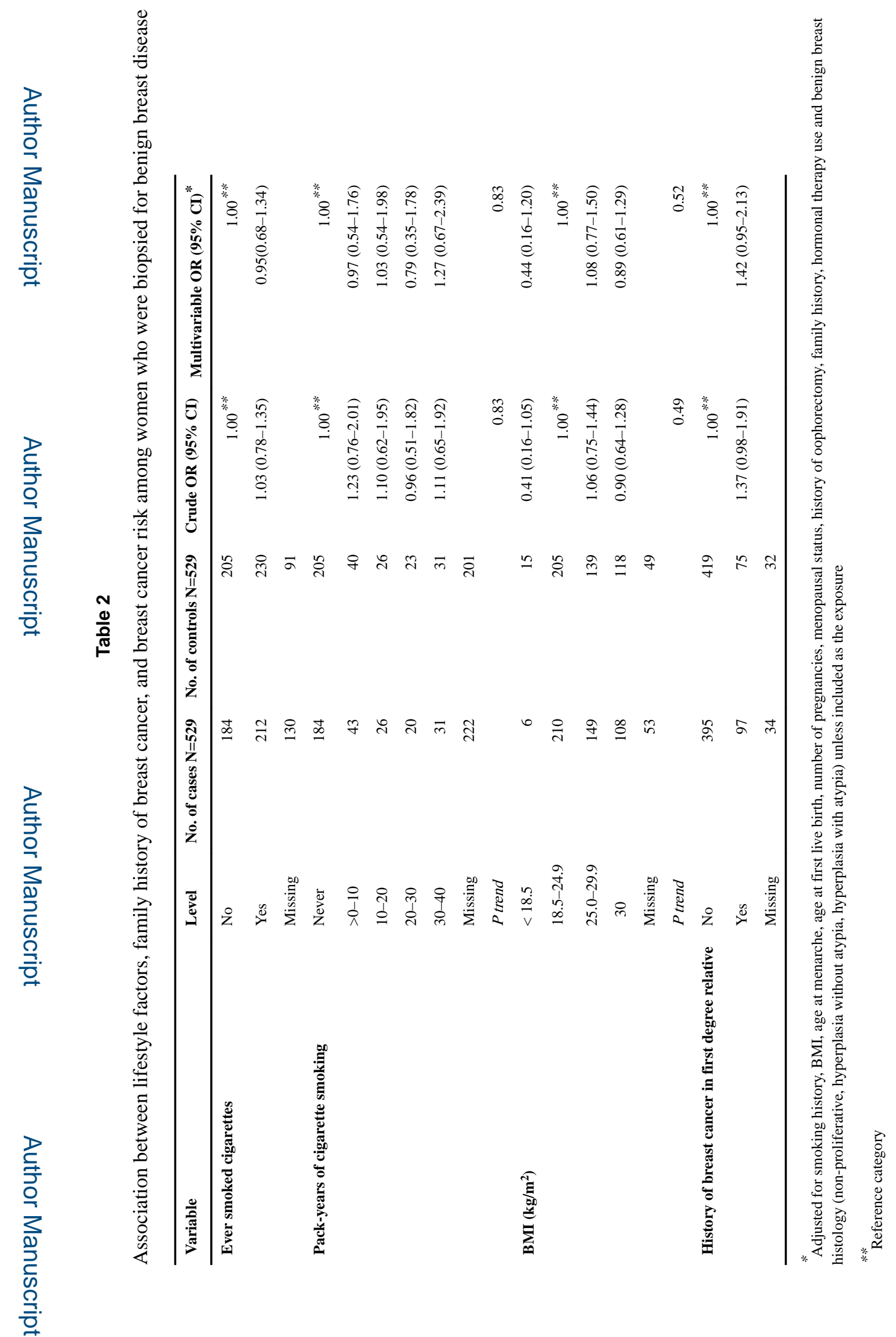

Breast Cancer Res Treat. Author manuscript; available in PMC 2018 October 01. 


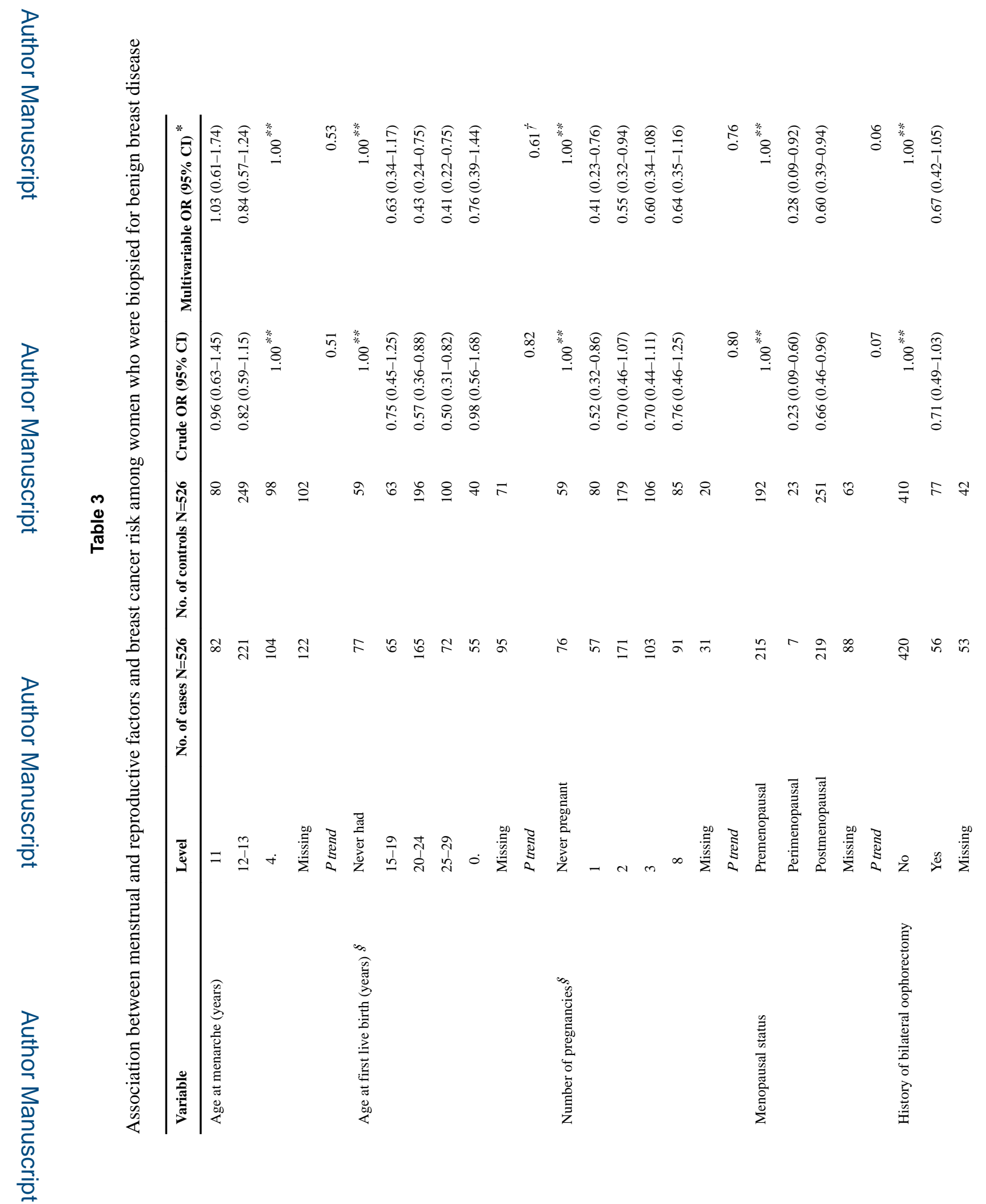

Breast Cancer Res Treat. Author manuscript; available in PMC 2018 October 01. 
Arthur et al.

Page 15

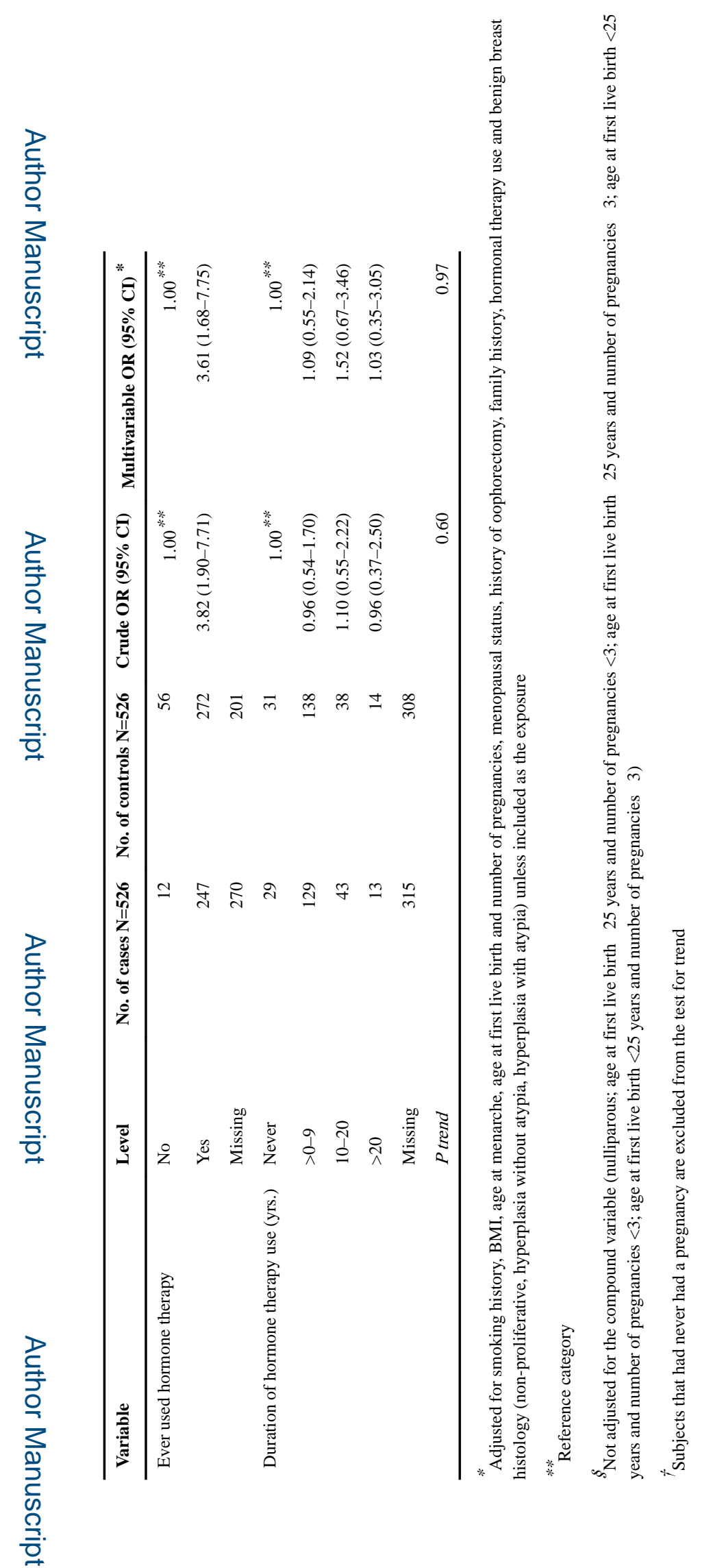

Breast Cancer Res Treat. Author manuscript; available in PMC 2018 October 01. 
Table 4

Association between lobular involution and breast cancer risk among women who were biopsied for benign breast disease

\begin{tabular}{|c|c|c|c|c|}
\hline Lobular involution & No. of cases & No. of controls & Crude OR (95\% CI) & Multivariable OR $(95 \% \mathrm{CI})$ * \\
\hline No & 105 & 98 & $1.00^{* * *}$ & $1.00^{* *}$ \\
\hline Yes & 204 & 238 & $0.90(0.76-1.06)$ & $1.04(0.66-1.63)$ \\
\hline \multicolumn{5}{|l|}{ Extent of involution } \\
\hline Absent & 105 & 85 & $1.00^{* *}$ & $1.00^{* * *}$ \\
\hline $1 \%-74 \%$ & 165 & 168 & $0.78(0.53-1.14)$ & $1.06(0.67-1.69)$ \\
\hline$\geqslant 9.6$ & 39 & 50 & $0.61(0.35-1.07)$ & $0.91(0.45-1.84)$ \\
\hline Ptrend & & & 0.25 & 0.72 \\
\hline
\end{tabular}

* Adjusted for smoking history, BMI, age at menarche, age at first live birth and number of pregnancies, menopausal status, history of oophorectomy, family history, hormonal therapy use and benign breast histology (non-proliferative, hyperplasia without atypia, hyperplasia with atypia)

**

Reference category 